\title{
La extensión en la formación de grado del Licenciado en Turismo. El proyecto "Concientización turística ambiental en destinos costeros"
}

\author{
Noelia Padilla \\ noeliamdq88@hotmail.com
}

Cristina Varisco

cvarisco@mdp.edu.ar

Graciela Benseny

gracielabenseny@gmail.com
Docentes investigadoras de la Universidad Nacional de Mar del Plata, Argentina.
Integración de la docencia y la extensión /

Intervenciones

RECEPCIÓN: 24/06/16

ACEPTACIÓN FINAL: 10/10/16

\section{Resumen}

Se presentan los resultados de las actividades llevadas a cabo en el proyecto de extensión "Concientización turística ambiental en destinos costeros", de la Universidad Nacional de Mar del Plata, con el objetivo de analizar la contribución de la extensión a la investigación y formación de grado del Licenciado en Turismo. Se articuló con la asignatura Práctica Profesional Comunitaria, en la que los estudiantes realizaron actividades de concientización en problemáticas ambientales dirigidas a diferentes actores y consensuaron acciones para mejorar la contribución del turismo al desarrollo local en Santa Clara del Mar (Argentina). Se aplicó la metodología de Investigación Acción Participativa (IAP), lo cual permitió que el accionar del grupo contribuya con la formación del Licenciado en Turismo mediante la capacitación en temas turísticos y ambientales, en tanto que su actuación generó una mayor conciencia en los actores locales sobre el adecuado manejo de los espacios turísticos y costeros, con el consecuente favorecimiento del desarrollo local.

Palabras-clave

- Extensión

- Investigación

- Acción Participativa

- Actores sociales

- Turismo

\section{Resumo}

Aqui são apresentados os resultados das atividades desenvolvidas no projeto de extensão "Conscientização turística ambiental em destinos litorâneos" da Universidade Nacional de Mar del Plata, com o objetivo de analisar a contribuição da extensão para a pesquisa e formação do Bacharel em Turismo. O Projeto foi articulado com a disciplina Estágio Profissional Comunitário, onde os estudantes realizaram atividades de conscientização sobre problemas ambientais, dirigidas a diferentes atores, e acordaram ações para melhorar a contribuição do turismo com o desenvolvimento local, em Santa Clara del Mar (Argentina). Utilizou-se o método de pesquisa Ação Participativa (AP), que permitiu que a ação do grupo contribuísse para a formação do Bacharel em Turismo através da capacitação em temas turísticos e ambientais. A performance do grupo gerou maior consciência nos atores locais sobre a gestão adequada dos espaços turísticos e litorâneos, beneficiando o desenvolvimento do lugar.

Palavras-chave

- Extensão

- Pesquisa

- Ação Participativa

- Atores sociais

- Turismo

\section{Para citación de este artículo}

Padilla, N.; Varisco, C. y Benseny. G. (2016). La extensión en la formación de grado del Licenciado en Turismo. El proyecto "Concientización turística ambiental en destinos costeros". En Revista +E versión digital, (6), pp. 216-223. Santa Fe, Argentina: Ediciones UNL. 


\section{Introducción}

La transferencia de conocimiento desde la universidad hacia la comunidad se convierte en una función social relevante de esta institución, basada en el compromiso social y el trabajo en conjunto de estudiantes, docentes e investigadores articulados con la comunidad. Este escrito presenta los resultados de las actividades llevadas a cabo en el proyecto de extensión "Concientización turística ambiental en destinos costeros" que surge de la investigación "Turismo y desarrollo en destinos costeros de la Provincia de Buenos Aires", ambos llevados a cabo en Universidad Nacional de Mar del Plata durante el período 2013-2015 e insertos en la carrera de Licenciado en Turismo.

Específicamente, las actividades se implementaron en la localidad de Santa Clara del Mar, partido de Mar Chiquita, Argentina (Figura 1). Posee una población de 7713, habitantes según datos del Censo 2010 (Instituto Nacional de Estadísticas y Censos, INDEC) y constituye una localidad marítima especializada en turismo. Conforme a la Organización Mundial del Turismo (OMT) (1999), el turismo incluye las actividades que realizan las personas durante sus viajes y estadías en lugares diferentes a su entorno habitual por un período de tiempo consecutivo inferior a un año con fines de ocio, negocios y otros motivos no relacionados con el ejercicio de una actividad remunerada en el lugar visitado.

El turismo repercute en los territorios, aumenta la presión urbana y genera impactos ambientales que requieren de la concientización de los actores locales. En los destinos litorales, el avance urbano originado por las obras de infraestructura y equipamiento lleva a la transformación del ambiente costero y, tal como menciona Pearce (1991), estos cambios físicos alteran la apreciación visual y producen un efecto de urbanización homogénea. En concordancia con Vera Rebollo y otros (1997), las playas y las dunas expuestas a la actividad recreativa poseen alta vulnerabilidad y propensión a la modificación del hábitat, lo que altera la vida silvestre y destruye el medio ambiente.

En consecuencia, se presentan algunos problemas ambientales entendidos como:

"aquellas interrelaciones entre la sociedad y el medio físico (transformado o no) que generan directa o indirectamente consecuencias negativas sobre la salud de la población presente o futura y sobre sus actividades (y relaciones) sociales; pueden provocar un impacto negativo sobre los componentes de la flora y fauna, y alterar las condiciones estéticas y sanitarias del ambiente". (Herrero, 2004:166)

Como la intensificación de la erosión, el crecimiento de residuos contaminantes en la arena, la presencia de usos incompatibles, la reducción de los períodos de heliofanía y los cambios en las condiciones climáticas producto de edificios en altura, entre otros. En este sentido, el desarrollo turístico de Santa Clara del Mar se ha dado de manera rápida y espontánea, sin un plan de desarrollo turístico que permita reducir la presión urbana sobre los recursos naturales del litoral y mitigar los problemas ambientales. Atento a ello, el proyecto de extensión tuvo como objetivo concientizar a los actores locales sobre los problemas ambientales de su litoral y proponer acciones que mejoren la contribución del turismo al desarrollo local.

Las actividades fueron integradas a la cátedra Práctica Profesional Comunitaria de la carrera de Licenciado en Turismo. La temática deriva de la escasez o ausencia de asignaturas con esta orientación en las opciones educativas de la ciudad de Mar del Plata y en el país, a pesar de la extensión, diversidad y problemáticas que presenta la costa argentina.

Con estos lineamientos, la articulación investigación-extensióndocencia se propuso como una instancia formativa en la carrera de Licenciado en Turismo para complementar una formación integral, retroalimentada por la investigación, y promover la reflexión crítica sobre la propia práctica.

Por lo planteado, el objetivo general de este artículo es analizar la contribución de la extensión a la investigación y formación del Licenciado en Turismo basado en la metodología de Investigación Acción Participativa (IAP) a partir del mencionado proyecto de extensión "Concientización turística ambiental en destinos costeros".

\section{Figura 1. Localización de Santa Clara del Mar}

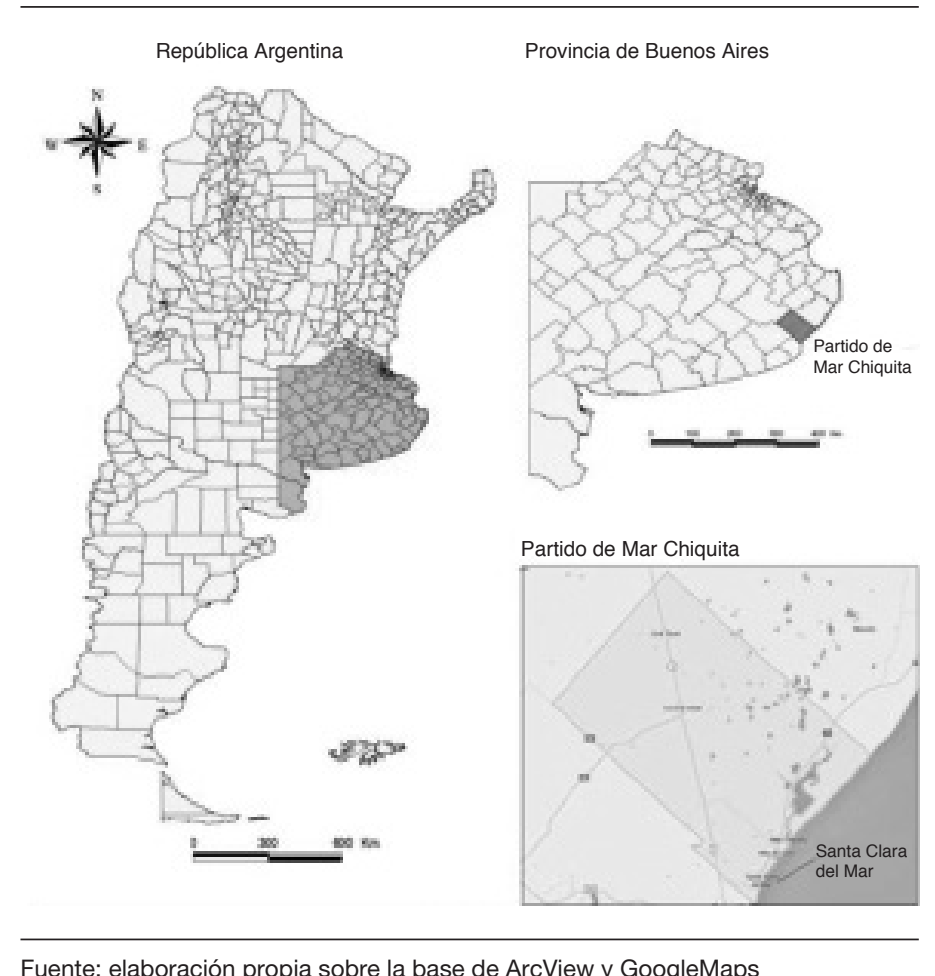




\section{Marco teórico-metodológico}

Tal como menciona Tünnermann (2003), la extensión universitaria tiene por misión proyectar, en la forma más amplia posible y en todas las esferas de la Nación, los conocimientos, estudios e investigaciones de la Universidad para permitir a todos participar en la cultura universitaria, contribuir al desarrollo social y a la elevación del nivel espiritual, moral, intelectual y técnico del pueblo. Para Freire (2010), la extensión universitaria es un modo de comunicar el conocimiento a los estudiantes y/o a los sectores populares, para lo cual son fundamentales la idea de diálogo, interacción y reflexión dialéctica. La generación de conciencia es fructífera si se inscribe en un proceso pedagógico que tienda a la autonomía y libertad y nunca a la manipulación.

El análisis de Serna Alcántara (2007) permite inferir diversos tipos de extensión que surgieron a través de la historia y que se encontraban vigentes al inicio del siglo XXI:

"a) Altruista: proyectos de extensión generados para brindar apoyo a sectores marginados. Se considera una retribución a los sectores que financian con sus impuestos las universidades públicas sin acceder a ellas. Por ejemplo: apoyo educativo en barrios marginales.

b) Divulgativo: aspira a comunicar los avances técnicos, científicos y la cultura universitaria a la sociedad, bajo el supuesto de que sólo es necesario adaptar el lenguaje de transmisión. Este modelo 'nace de la supuesta preocupación de las universidades por elevar la cultura de la población y por tanto su bienestar, difícilmente se revela como respuesta a las auténticas necesidades y anhelos de los sectores mayoritarios de la sociedad'.

c) Concientizador: se vincula con el objetivo de generar conciencia crítica, social y política, que se nutre principalmente del pensamiento de Paulo Freire y se asocia a la acción transformadora de la realidad.

d) Vinculatorio empresarial: sostiene la necesidad de adaptar la formación y la investigación a los requerimientos de las empresas. La vinculación se produce a través de servicios vendidos por las universidades al sector privado y.... 'las necesidades sociales son identificadas como análogas a las de empresas y en consecuencia los universitarios deberán ser educados para atender estas necesidades'”. (Serna Alcántara, 2007:3-4)

A estas formas de concebir la extensión, puede agregarse un modelo adicional denominado "desarrollo integral" (González, 2003, citado por Sastre, 2014), por el cual la Universidad asume un rol social y crea instancias de acción para mejorar la calidad de vida de la población. Este modelo parece el más pertinente para encuadrar las actividades vinculadas al desarrollo local cuando la metodología implica una intervención directa en el territorio.
El desafío de la extensión universitaria en la actualidad consiste, según Rofman y Vázquez Blanco, en generar interacción social y paralelamente ampliar las experiencias que integran la extensión con la investigación y la docencia. Por ello, los autores mencionan:

"el vínculo universidad-sociedad debía ser el resultado de un proceso bidireccional, dinámico y dialéctico de interacción social, donde la Universidad propaga los resultados de la docencia, la investigación y la cultura, recibiendo de aquella aportes para su incorporación, sistematización científica y retroalimentación". (2006:32)

De esta manera, la articulación extensión-docencia reviste una instancia que completa la formación integral de los futuros profesionales al promover la reflexión crítica sobre la propia práctica. Esta articulación se hace manifiesta puesto que reconoce el valor de la generación transdisciplinar de conocimiento, en el sentido de considerar el aporte de diferentes actores sociales a la solución de problemas concretos en un proceso colaborativo.

Tal como explica Schuster (2004), entre la multiplicidad de métodos que pueden utilizarse en las ciencias sociales, la investigaciónacción tiene por finalidad explícita generar conocimiento y transformar la realidad. En este sentido, la IAP favorece una integración entre la extensión-investigación-docencia que, como metodología, se inicia con una demanda social, generalmente formulada de manera explícita. Luego se elabora el proyecto mediante un mecanismo de negociación con los sectores o instituciones demandantes y tanto el diagnóstico como la propuesta se comparten para que pueda producirse una interacción real entre todos los involucrados y un trabajo colaborativo.

Al respecto, Greenwood señala:

"la prueba de la validez de la investigación-acción no es su aceptación por una comunidad de investigadores expertos, sino que se juzga entre los dueños locales del problema en cada situación específica. Si tienen suficiente confianza en los resultados para tomarse el riesgo personal y social de actuar de acuerdo con ellos, se considera un resultado válido". (2000:34)

De modo especial, esta cuestión plantea la dificultad de producir una verdadera participación de los sectores involucrados en el proyecto, en oposición a prácticas meramente convalidatorias de decisiones tomadas por el equipo académico. Con relación a la actividad turística, Robledo afirma:

"esta forma participativa de investigar contribuye, de igual manera, con la recuperación del saber tradicional de la cultura local permitiendo así que los nuevos conocimientos surjan o se validen sobre la base concreta de lo ya poseído por los sujetos sociales, valorizando la vida cotidiana como el marco concreto de la identidad, y por lo tanto, prevenir extrañamientos". (2007:1) 


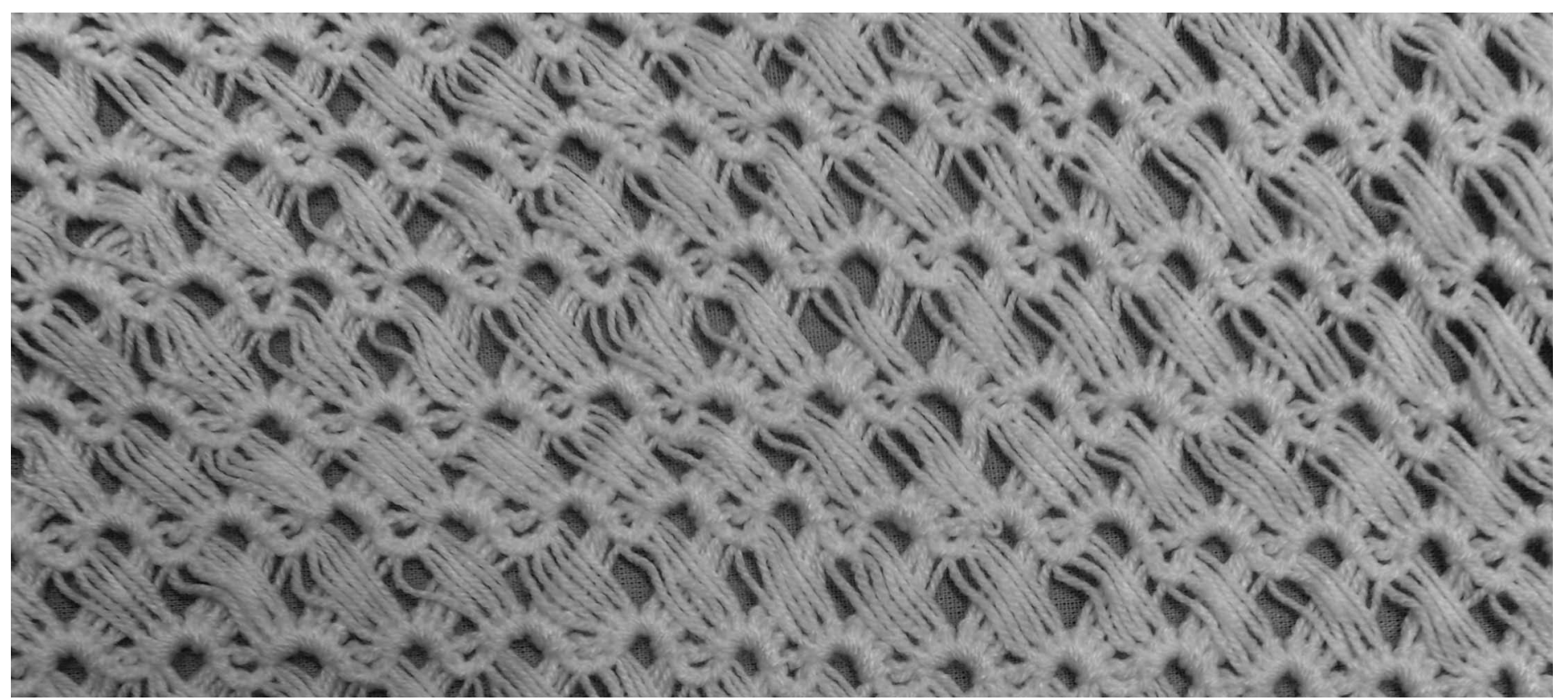

(c) Claudio Siboldi

La IAP es un proceso que origina ciertos desafíos y contrasta a la concepción tradicional de ciencia. Por un lado, intenta romper con la oposición teoría-práctica en tanto reconoce la necesidad de articular ambas formas de conocimiento en la acción social; y por otro, la dicotomía entre sujeto que conoce y objeto de investigación es superada por la búsqueda de consensos que requiere de un diálogo profundo basado en el respeto a las personas que participan de estas experiencias sin pertenecer al ámbito académico (Ortiz, 2008).

\section{Resultados}

El análisis de esta experiencia de articulación entre investigación, docencia y extensión se presenta a partir de las etapas de la IAP planteadas en Varisco y otros (2015): inicio del proyecto, planificación, conformación del grupo, desarrollo, sistematización de la experiencia, validación del conocimiento y retroalimentación del proyecto.

El inicio del proyecto surgió a partir de una demanda concreta a la Universidad por parte de integrantes de la Cámara de Comercio del Partido de Mar Chiquita en el año 2011. Se observó el interés de los actores locales y la necesidad de formalizar la actividad del equipo. La planificación consideró la negociación entre los demandantes del proyecto y el equipo de investigación. El proyecto fue diseñado según los requisitos formales de las áreas de investigación y extensión de la Universidad y se insertó en el Grupo de Investigación Turismo y Territorio: Espacios Naturales y Culturales de la carrera de Licenciado en Turismo. Se presentó la propuesta a la Secretaría de Turismo de la localidad demandante y se tomaron como insumo los tres antecedentes de planificación turística del Partido de Mar Chiquita (Comisión de Turismo, Codetur, Cámara de Empresarios y Plan Estratégico oficial) formulados pero no implementados. En cuanto a la temática, los motivos, requerimientos, conveniencia y oportunidad de incorporar la dinámica sistémica y problemáticas se basan en la necesidad de producir acciones comprometidas con la sociedad y la concientización de los problemas territoriales y ambientales mediante la práctica de una educación integral, en la que intervienen no sólo la comunidad educativa sino también todos los actores sociales involucrados en el tema (funcionarios públicos, sector privado, organizaciones de la sociedad civil, comunidad local, etc.), con los cuales se interactúa de modo permanente. Con relación a la conformación del grupo, estuvo integrado principalmente por docentes y estudiantes de la carrera de Licenciado en Turismo que cursaban la cátedra Práctica Profesional Comunitaria. También por estudiantes y graduados de otras disciplinas, como Tecnicatura en Gestión Cultural, Licenciatura en Geografía y Profesorado de Arte y Contabilidad. Generó una experiencia interdisciplinaria muy interesante y fructífera dada la diversidad de miradas sobre el turismo en la localidad. Si bien no existió una incorporación formal de actores locales, durante el proceso de implementación se consolidó el trabajo conjunto con integrantes de la Secretaría de Turismo y se afianzaron los vínculos con algunos emprendedores locales. 
La Práctica Profesional Comunitaria es el proceso mediante el cual los estudiantes formalizan las habilidades y conocimientos adquiridos durante su formación profesional, entendida como un período que posibilita validar, en un contexto laboral, los aprendizajes obtenidos en la etapa formativa. Además, reintegran a la sociedad lo brindado mediante la educación pública.

En el caso particular de los estudiantes que optaron por participar en el proyecto de extensión, la cátedra apuntó a la consolidación de un espacio motor de aprendizaje y búsqueda del conocimiento de las problemáticas ambientales en destinos litorales y la relación entre turismo y desarrollo local a los efectos de mejorar la articulación docencia-acción en el tema.

Estas actividades contribuyeron a fortalecer el perfil del Licenciado en Turismo que está determinado por poseer las actitudes, aptitudes y conocimientos que le permitan desempeñarse tanto en el ámbito público como privado. A su vez, tienen que ser profesionales insertos en la realidad social en la que intervienen, con espíritu crítico e innovador, sobre la base de valores éticos, solidarios y humanitarios, con capacidad para comprender la problemática de la disciplina, generalista y con especial idoneidad para actuar en organizaciones propias de la especialidad.

El desarrollo del proyecto apunta a un proceso de generación de conocimiento en espiral, con sucesivos diagnósticos, propuestas y evaluaciones. Efectivamente, el proyecto implicó la implementación de encuestas semiestructuradas realizadas por los estudiantes bajo la supervisión de docentes. Tuvieron el objetivo de conocer el perfil y opinión de los turistas respecto de las características del destino. Se realizaron 165 encuestas durante la Semana Santa de 2014, y se establecieron como puntos de toma de encuestas distintos sitios turísticos de la localidad de Santa Clara del Mar (Tablas 1 y 2). Los resultados destacan la "tranquilidad" del destino como un gran recurso intangible de la localidad, así como la "playa", el "mar" y la "costa" como imágenes representativas.

Luego realizaron charlas/talleres en establecimientos educativos. Esta actividad fue llevada a cabo principalmente por los estudiantes bajo la supervisión de un docente. Se seleccionaron distintas instituciones educativas (Escuela Municipal $n^{\circ} 16$, Nuestra Señora del Camino, Instituto María Auxiliadora) y diferentes años, incluido preescolar, primario y secundario. De acuerdo con cada nivel se realizaron diversas actividades educativas, entre ellas proyecciones de videos y Power Point y juegos grupales. Tuvo asimismo una instancia de diálogo y reflexión atendiendo a los principios de la educación ambiental. Los estudiantes pudieron transferir los conocimientos adquiridos en el ámbito universitario a través de la capacitación y concientización en problemáticas costeras, adaptándose al ritmo de cada grupo en las distintas instancias educativas.

Finalmente se llevaron a cabo talleres con docentes y empresarios que consideraron como ejes el sistema turístico y la cuestión ambiental. El primer taller fue dirigido a docentes aunque se amplió
Tabla 1

\begin{tabular}{|c|c|c|}
\hline \multicolumn{2}{|l|}{ Datos del encuestado } & \multirow{2}{*}{$\frac{\text { Frecuencia (\%) }}{26}$} \\
\hline Procedencia & CABA & \\
\hline & Gran Bs. As. & 22 \\
\hline & Prov. Bs. As. & 50 \\
\hline & Otras Prov. & 1 \\
\hline \multirow[t]{6}{*}{ Estadía } & 1 día & 7 \\
\hline & 2 días & 5 \\
\hline & 3 días & 8 \\
\hline & 4 días & 43 \\
\hline & 5 o más días & 8 \\
\hline & n.s./n.c. & 10 \\
\hline \multirow[t]{6}{*}{ Tipo de alojamiento } & Vivienda propia & 52 \\
\hline & Vivienda alquilada & 25 \\
\hline & Vivienda prestada & 20 \\
\hline & Hotel 1 estrella & 2 \\
\hline & Hostería 1 estrella & 1 \\
\hline & Otros sin especificar & 1 \\
\hline
\end{tabular}

Fuente: Proyecto "Concientización turística ambiental en destinos costeros" (2014)

la convocatoria a escuelas del partido de Mar Chiquita, y se basó en los principios de la educación ambiental. Los docentes manifestaron algunas problemáticas, como el avance de la erosión costera y la presencia de residuos en playas.

El segundo taller se dirigió a empresarios, comerciantes y emprendedores de diversos rubros, como gastronomía, alojamiento, balneario, inmobiliaria, entre otros. Constituyó un disparador de la necesidad de trabajo en conjunto sobre la base de la interdependencia de los servicios turísticos. Estos talleres fueron realizados en conjunto con funcionarios de la Secretaría de Turismo y la Cámara de Comercio de Mar Chiquita.

Dada la alta conflictividad de algunos temas vinculados a impactos ambientales y las dificultades detectadas para el trabajo conjunto con el sector público y entre los actores privados, en un primer taller el tema identidad se propuso como punto de partida y factor aglutinador sustentado en los rasgos compartidos por todos los actores locales. En un taller posterior se retomó el diagnóstico y se dio como consigna generar propuestas para implementar en el corto y mediano plazo. El objetivo de esta instancia fue trascender la etapa de críticas y producir los primeros resultados con actividades como visitas guiadas, feria gastronómica y muestra de fotografías, que involucraban al sector público y a los prestadores privados. De ello se concretó una muestra fotográfica en cuya organización participó la Secretaría de Turismo. Se llevó a cabo en vacaciones de invierno de 2015 en el Centro Cultural de Santa Clara del Mar y participaron vecinos de la localidad que aportaron sus fotografías en forma gratuita. 
Tabla 2

\begin{tabular}{|c|c|c|c|}
\hline \multicolumn{3}{|c|}{ Opinión sobre el destino, según turistas } & \multirow{3}{*}{$\begin{array}{l}\text { Frecuencia (\%) } \\
9 \\
6\end{array}$} \\
\hline \multicolumn{2}{|l|}{ Motivos de elección } & Encuentro con familiares y amigos & \\
\hline & & Descanso & \\
\hline & & Conocer nuevos destinos & 4 \\
\hline & & Deporte & 2 \\
\hline & & Pesca & 2 \\
\hline & & Trabajo/negocios & 1 \\
\hline & & Total & 24 \\
\hline \multirow{3}{*}{\multicolumn{2}{|c|}{ Características diferenciales }} & Tranquilidad & 32 \\
\hline & & Cercanía a Mar del Plata & 10 \\
\hline & & Seguridad & 1 \\
\hline \multirow[t]{17}{*}{ Imágenes percibidas } & Atributos tangibles & Playa, mar, costa & 26 \\
\hline & & Productos gastronómicos (alfajores, pescado) & 4 \\
\hline & & La Posta del Ángel & 4 \\
\hline & & Cerveza & 2 \\
\hline & & Rotonda del Viejo Contrabandista & 2 \\
\hline & & Camet Norte & 2 \\
\hline & & Pesca & 2 \\
\hline & & Naturaleza/verde & 1 \\
\hline & & Artesanías & 1 \\
\hline & & Campo en cercanías & 1 \\
\hline & Atributos intangibles & Tranquilidad/paz/silencio/descanso & 41 \\
\hline & & Ambiente familiar & 8 \\
\hline & & Seguridad & 3 \\
\hline & & Recuerdos infancia & 2 \\
\hline & & Paisaje, vista, entorno & 2 \\
\hline & & Carácter agreste & 2 \\
\hline & & Ambiente de amistad & 2 \\
\hline
\end{tabular}

Fuente: Proyecto "Concientización turística ambiental en destinos costeros" (2014)

La sistematización de la experiencia implicó la generación de conocimiento durante todo el proceso a raíz de la interacción de los actores locales con el grupo de trabajo. Cada actividad se registró en actas de reuniones, programas, materiales de difusión y fotografías. No obstante, la posibilidad de sistematizar los resultados de forma tal que se retroalimente el marco teórico de la investigación es lo que permite diferenciar este tipo de proyecto de extensión. Se asume como un desafío la búsqueda de equilibrio entre la perspectiva crítica, necesaria para la producción académica, y la posición conciliadora para cumplir con el rol mediador de la Universidad entre el sector público y el privado.

La validación del conocimiento combina la evaluación inherente al sistema de ciencia y técnica llevada a cabo por pares con la evaluación de los actores locales. En este sentido, las actividades implementadas en Santa Clara del Mar constituyeron un avance gradual en la concientización ambiental y en la articulación entre actores locales, en tanto que un indicador favorable ha sido el reconocimiento explícito de los participantes en los talleres del rol mediador de la Universidad en la dinámica sociopolítica.

Finalmente, la retroalimentación del proyecto aspira a dar continuidad al proceso iniciado contemplando dos ajustes: consultar las necesidades percibidas por los actores de los sectores público y privado, que puedan proponer acciones de capacitación y reflexión, y avanzar de manera más concreta hacia una planificación turística. El desafío de esta segunda etapa se basa en el fortalecimiento de las capacidades locales de forma tal que no se genere una dependencia respecto de la Universidad y que al finalizar el proyecto las instituciones asuman el liderazgo necesario para el desarrollo local. En cuanto al proyecto de investigación, también se ha iniciado una segunda etapa vinculada al proyecto de extensión. 


\section{6}

la validación del conocimiento combina

la evaluación inherente al sistema de

ciencia y técnica llevada a cabo por pares

con la evaluación de los actores locales

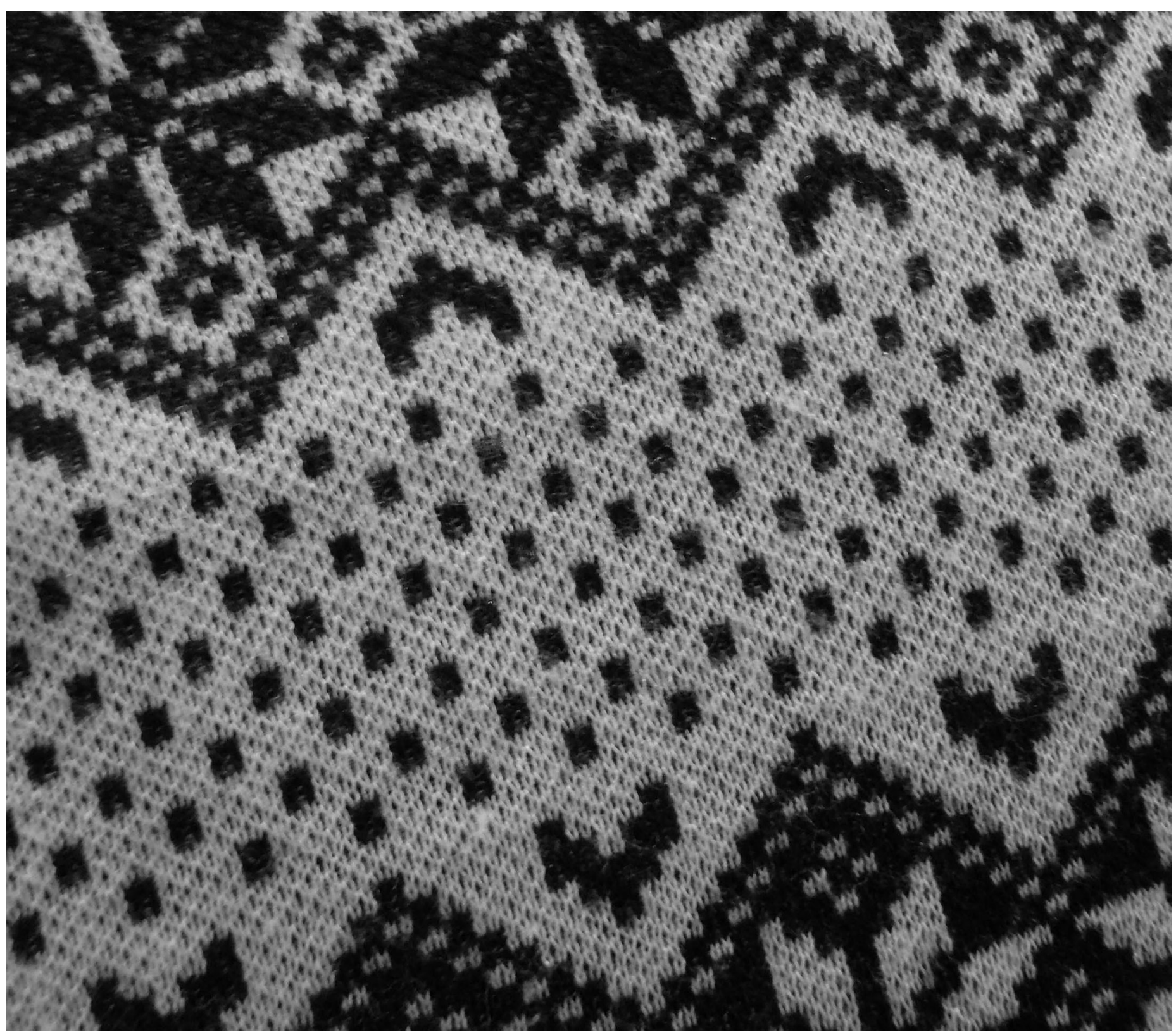

(C) Hugo Pascucci 


\section{Conclusiones}

A través del proyecto de extensión "Concientización turística ambiental en destinos costeros" se realizaron actividades de capacitación y concientización turística y ambiental mediante el trabajo participativo que vinculó actividades de docencia, investigación y extensión universitaria, con la colaboración de las autoridades locales y la participación de la comunidad, a fin de lograr un cambio de conducta social que encamine estrategias de acción en comunidades costeras.

Desde el punto de vista de la docencia, en el marco de la cátedra Práctica Profesional Comunitaria, el proyecto contribuyó a la formación del profesional en turismo mediante la capacitación en temas turísticos y ambientales y la participación en actividades de coordinación y organización de grupos diversos.

La implementación de encuestas reveló que la tranquilidad y la playa constituyen los principales recursos turísticos del lugar. A su vez, la tranquilidad es una ventaja competitiva frente a otros destinos con características físico-naturales compartidas. Los talleres en colegios atendieron la necesidad de conservar estas características, pese a un mayor desarrollo urbano, con base en la implementación de buenas prácticas y la integración de los actores sociales. Los estudiantes transfirieron los conocimientos adquiridos en su formación de grado y asumieron el compromiso social en la identificación, mitigación y/o resolución de algunas problemáticas de la localidad.

Desde la práctica de la investigación fue posible observar la utilidad de las perspectivas teóricas y el conocimiento de las demandas locales que fue aportado por diversos actores, tales como empresarios, comerciantes, artesanos, docentes, a través de talleres participativos. Surgió la necesidad del trabajo en conjunto entre los prestadores de servicios y el sector público y la realización de actividades turísticas comprometidas ambientalmente. La implementación de una muestra fotográfica resultó efectiva para iniciar un proceso de aprendizaje colectivo con la realización de actividades concretas. La sistematización del proceso permitió efectivamente retroalimentar la investigación con nuevos interrogantes, que incluyen la intervención en el territorio como desafío.

El desarrollo turístico se asume como un proceso necesariamente participativo donde deben intervenir representantes de los distintos sectores para delinear políticas y diseñar planes a fin de lograr un desarrollo turístico sustentable e integral. La metodología de IAP hace explícita esta articulación y reconoce el valor de la generación transdisciplinar de conocimiento al recibir el aporte de distintos actores sociales para solucionar situaciones conflictivas.

\section{Referencias bibliográficas}

Freire, P. (2010). ¿Extensión o comunicación? La concientización en el medio rural. México: Siglo XXI Editores.

Greenwood, D. J. (2000). De la observación a la investigación-acción participativa: una visión crítica de las prácticas antropológicas. Revista de Antropología Social, 9, 27-49.

Herrero, A. C. (2004). Problemas Ambientales Urbanos. En Di Pace, M. y otros, Ecología de la Ciudad. Buenos Aires: Prometeo Libros.

Pearce, D. (1991). Desarrollo turístico. Su planificación y ubicación geográfica. México: Trillas.

Robledo, M.; Rodríguez, O.; Castro, H.; Marun, R.; y Toro, I. (2007). Contribuciones de Investigación Acción Participativa en Microrregiones de San Juan para la construcción de Productos Turísticos y el Desarrollo Local Sustentable y Sostenible. Caso Médano de Oro. En VIII Jornadas Nacionales y II Simposio Internacional de Investigación y Acción en Turismo, CONDET. Posadas, Argentina: Universidad Nacional de Misiones.

Rofman, A. y Vázquez Blanco, J. M. (2006). La extensión universitaria en tiempos de crisis económico-social: La experiencia de la Facultad de Ciencias Económicas de la Universidad de Buenos Aires en el lapso 2004-2006. Cienc. docencia tecnol [online], 32, 9-48.

Schuster, F. (2004). El Método en las Ciencias Sociales. Buenos Aires: Editores de América Latina.

Serna Alcántara, G. A. (2007). Misión social y modelos de extensión universitaria: del entusiasmo al desdén. Revista Iberoamericana de Educación, Organización de Estados Iberoamericanos para la Educación, la Ciencia y la Cultura (OEI), 43. Tünnermann Bernheim, C. (2003). La Universidad latinoamericana ante los retos del siglo XXI. México: Colección UDUAL.

Varisco, C.; Benseny, G.; Castellucci, D.; González M.G.; Padilla, N.; Muñoz M.J. y Cesar, C. (2015). La extensión universitaria como forma de implementar la investigación-acción participativa. En VII Simposio Internacional y XIII Jornadas Nacionales de Investigación - Acción en Turismo, CONDET Congreso Internacional de Turismo. Neuquén, Argentina: Universidad Nacional de Comahue. Vera Rebollo, F.; López Palomeque, F.; Marchena Gómez, M. y Antón Clave, S. (1997). Análisis territorial del turismo. Una nueva geografía del turismo. Barcelona: Ariel. 